\title{
The potential of MOOCs for large-scale teacher professional development in contexts of mass displacement
}

\author{
Eileen Kennedy* and Diana Laurillard - UCL Institute of Education, UK
}

\begin{abstract}
The mass displacement of people across the world, currently estimated at 65 million, creates a massive demand for new forms of education for children, young people and adults. However, this cannot be addressed without attending to what this means for teachers and other professionals involved in education and training. Clearly, there is a need for large-scale teacher professional development (TPD). Digital technology has the potential to meet this demand, but challenges are presented by the poor digital infrastructure in contexts of mass displacement. Data from two projects are analysed to explore the viability of scaling up TPD in the form of co-designed massive open online courses (MOOCs). The first data set is from a co-designed TPD MOOC project Blended Learning Essentials, to show that digital technology can be effective for scaling up TPD, but that a sustainability plan must be in place from the outset. The second data set is from a project that built on the first to run stakeholder co-design workshops in Lebanon, as a way of developing large-scale TPD in this most challenging context. Lebanon has the highest proportion of refugee to host communities in the world. This case study indicates that MOOCs could be viable in such a context, but also highlights the need to balance the generic principles being offered with a focus on localized practice. A theory of change is presented to outline a method of meeting these challenges by employing a co-design methodology to create self-sustaining digital TPD in the context of Lebanon, and to test this model with the contexts of mass displacement experienced by other participants in the MOOC.
\end{abstract}

Keywords: teachers; MOOCs; refugees; theory of change; co-design

\section{Introduction}

Over half of the world's refugees are children, with the majority likely to spend their entire childhoods away from home with limited access to education (Sesnan et al., 2013). Education can be a powerful tool for those affected by conflict and mass displacement, building hope, understanding and resilience. Yet, in conflict-affected areas, the 'Maslovian' pressure to meet basic needs, such as safety, food and shelter (Burns and Lawrie, 2015: 17), can draw attention away from meeting children's needs for learning. Without access to education, however, children's capacity to flourish is substantially reduced - and, as years without education increase, the negative effects multiply. To learn effectively, vulnerable children need skilled and sensitive teachers. However, the numbers of teachers within affected communities are reduced in emergencies, through displacement, intimidation or physical and psychological harm they have suffered (Burns and Lawrie, 2015). Moreover, the influx of refugees puts pressure on 
many services provided by the host nation, including the education system. The need for more teachers is pressing in such circumstances, and those teachers need to be professionally equipped for the situations they face. The quality of teachers has been well established as key to promoting learning even in the most well-resourced schools (Darling-Hammond, 2000; Ring and West, 2015), but few teachers have been trained to respond to the diverse needs of children affected by conflict and displacement.

To address the gap in the provision of teacher professional development (TPD), we set out to test the extent to which a new co-design model of large-scale online TPD using massive open online courses (MOOCs) could improve conditions, even in these highly challenging contexts. Lebanon is the most extreme case, where a quarter of the population are refugees, and 'a large part of the burden of providing education to all refugee children from Syria rests on the teachers, and they are generally unprepared to face their task' (Akar and van Ommering, 2018: 8). This context would provide a good test of a new model because the lessons being learnt are likely to resonate with many other such contexts around the world.

This article describes the use of a co-design model in a previous $\mathrm{MOOC}$ project to offer TPD on a large scale, and demonstrates the benefit of being responsive to teachers' needs, and of engaging their experience and expertise in developing new solutions to education challenges.

In a context such as Lebanon, teachers thrust into circumstances for which they have had no training are working hard to respond, but the literature suggests that teachers' voices are often excluded from dialogue around ways to address the issues they face (Richardson et al., 2018).

In such contexts, large-scale TPD is needed urgently, but it cannot take the conventional $\mathrm{MOOC}$ form of a unidirectional expert update. It must be co-designed, enabling the sourcing, exchange and collaborative development of teacher community knowledge. The article goes on to describe the early stages of testing whether the co-design model for large-scale TPD is feasible in the context of extreme mass displacement, such as Lebanon.

Our approach is to evaluate the extent to which a MOOC platform and digital tools can orchestrate the process of knowledge building by the whole community of participants on how to teach in the most challenging contexts.

\section{The potential of MOOC technology for scaling up TPD}

$\mathrm{MOOC}$ technology has the potential to enable learning at scale that is flexible enough to meet the needs of diverse groups of participants. There are three dimensions to digital delivery that enable this:

- removal of space and time limitations that restrict campus-based delivery to relatively small numbers

- efficiency achieved by creating learning activities as one-off, fixed costs that can be used multiple times

- digital support for automated feedback and peer review at scale, which can go some way to replace individualized tutor feedback. (Laurillard and Kennedy, 2017)

While traditional virtual learning environments offer tools that could be used to create effective learning environments, only the dedicated $\mathrm{MOOC}$ platforms were designed from the outset with scale in mind, to support hundreds of thousands of participants on whatever type of smartphone or digital device they have. 
Critiques of MOOCs have pointed to the ubiquitous high level of prior learning among those who participate (Hollands and Tirthali, 2014). However, this is inevitable, because MOOCs cannot offer sufficient pedagogical support to those without previous degree-level study (Rohs and Ganz, 2015): individualized communication between teacher and learner is not feasible on the large scale, which limits their appropriateness for inexperienced learners because of their greater need for teacher feedback. For educated professionals who are increasingly time poor, in need of flexible study options, are used to self-regulated, lifelong learning and are digitally literate, short MOOCs may provide the answer for professional development at scale (Laurillard, 2016).

We tested this approach in the Blended Learning Essentials (BLE) project, which was a response to the urgent need to support teachers in the vocational education sector who were expected to offer digital learning as part of their courses. The solution was to provide MOOCs that would demonstrate current methods of blended learning being used, and engage participants in discussing their contrasting merits and transferability to local contexts. The section 'Evaluating the form of a MOOC for TPD' below describes this project and evaluation in terms of the potential value of MOOCs for TPD at scale.

The second project was to investigate whether we could extend such an approach to the context of TPD for communities suffering mass displacement. The design of the second project was informed by the first - the BLE MOOC had many similarities to the MOOC proposed for Lebanon. BLE was a collaborative TPD MOOC that was both global and local - aimed at a specific sector in a specific country, but open to the world. It was also co-designed from the start, including involvement of vocational education and training (VET) teachers and trainers in videos, written resources and discussion facilitation. We argue that this can provide an evidential case for TPD on a large scale. The feasibility of the MOOC model for this specific context, with its multiple challenges, has yet to be established, however.

While MOOCs may offer cost-efficient, flexible and engaging professional development opportunities, the situation is complicated for those in many countries in the Global South where the requisite digital infrastructure - including access to broadband internet - is not necessarily in place. However, internet-enabled smartphone usage has substantially extended technological access to online learning globally. Among refugees, mobile phones have come to be considered a 'crucial resource akin to food', offering the means to acquire and disseminate information, make connections and navigate new environments (Wall et al., 2017: 241).

Access to the internet using a device can be impaired, however, because of poor signal coverage, the expense of connection or because of gendered patterns of control (Wall et al., 2017). In Africa, where low internet bandwidth is considered one of the biggest barriers to adoption of MOOCs, it has been proposed that internet access hubs be established (Oyo and Kalema, 2014) offering both mentoring and support for engaging in the courses, and opportunities to download resources for viewing/reading later.

The technological infrastructure presents but one set of challenges for providing digital TPD at scale in Lebanon. TPD in this context must be seen to be high quality, effective and practical and responsive to the very specific needs of the circumstances in which these teachers are working. Teachers need a curriculum that covers:

- meeting the needs of vulnerable children

- the skills and resources for teaching in these very challenging circumstances

- aspects of the initial teacher training they never received. 
They also need an approach that offers:

- flexible access to low-cost TPD

- certification of their training

- an understanding of their own traumatic experiences.

MOOC platforms are a plausible TPD solution because they do run on smartphones, provide flexible access to free TPD and offer low-cost certification from good universities. The online peer community could be a safe place for teachers to discuss and develop a shared understanding of their own experiences as refugees and as teachers in a challenging context. To invest in this approach in the contexts of mass displacement, however, we need compelling evidence that MOOCs are indeed effective for TPD at scale, and that such an approach would be viable with the complex and uncertain educational and technological infrastructure of Lebanon.

The section 'The potential of TPD MOOCs in the Lebanese context' below describes a project to test whether MOOCs could meet the target requirements for TPD at scale in Lebanon, guided by two research questions:

1. To what extent can MOOCs provide an effective form of TPD?

2. What is the potential for TPD MOOCs in the context of mass displacement in Lebanon?

\section{TPD in the context of mass displacement in Lebanon}

Lebanon has the highest per capita rate of refugees in the world (El-Ghali et al., 2017). Over half of the 1.5 million refugees are under the age of 18 (ibid.), with around 400,000 Syrian refugees of school age (UNHCR Operational Data Portal, 2018). Of these, only 200,000 children are in public schools in Lebanon (CLS, 2019a). There is an urgent need to improve the quality, reach and amount of education in order to reduce this excessive waste of human talent and aspirations.

The public school system is the less privileged education sector, but it absorbs most of the additional pressure from the influx of Syrian refugees. In 2014, the Ministry of Education and Higher Education, with the support of UNHCR, launched 'a second shift' (afternoon classes to accommodate Syrian students) for public schools to cope with the extra numbers (Beals, 2014). Despite these efforts, the experience of Syrian refugee children in public schools is poor, particularly in the second shift, where 100 per cent reported experiencing violence (CLS, 2019b). Syrian students struggle with the linguistic demands of the curriculum, since after Grade 6, maths and science are taught in French or English, while the Syrian curriculum is entirely in Arabic. Additionally, many Syrian students have spent time away from school, or have never been to school, and have not adapted to a formal learning environment (Shuayb et al., 2016). Moreover, the restrictions on adult labour for Syrian refugees encourages children to leave school to earn money to support their families, a decision they later regret (ibid.). This results in the appalling figure of only 2 per cent of Syrian refugee children attending secondary school (Shuayb et al., 2014). In addition to the public schools, the private and NGO sectors have become an indispensable part of education provision for refugees in Lebanon (ibid.).

Palestinian refugee students have had an even longer-term, poor-quality experience of education. The majority live in poverty and are denied rights to professional employment. Schools are organized by the United Nations Relief and Works Agency for Palestinian Refugees in the Near East (UNRWA), but are required to teach the Lebanese curriculum. There is a high drop-out rate, related to the 
incompatibility between their inclusion in the national curriculum and the students' marginalization from Lebanese society, as well as the quality of teaching and relationships with teachers (Shuayb, 2014b).

The provision of education for all these refugees in Lebanon is undertaken by a network of providers: Lebanese public schools (first and second shift); private schools (often affiliated to religious organizations); NGOs; and UNRWA. If refugee students are to receive the education they deserve, teachers in all these sectors need professional development. Teaching is a difficult and demanding profession, and teachers need support to meet the needs of vulnerable children. These teachers often experience the most difficult working conditions, and may have had traumatic experiences themselves (Burns and Lawrie, 2015). However, teachers in Lebanon do not all have the same access to professional development. Initial teacher training is provided by the Lebanese University (the sole public university in Lebanon) and by the private universities such as the Lebanese American University (LAU). However, the fees, particularly in the private university sector, can be prohibitive for many (over $\$ 8,000$ per term at LAU, for example).

For salaried teachers in public schools, continuing professional development is provided by the Centre for Development and Research (CERD) or the Ministry for Education and Higher Education (MEHE). Permanent salaried public school teachers must take at least one professional development module per year. However, increasing numbers of teachers are employed on a part-time contractual basis, and for these teachers, who are those most likely to teach in the second shift, continuing TPD is not required and teachers must engage voluntarily outside of paid work (Maamari, 2018). TPD is also provided in the private sector and by NGOs, where teachers are often refugees themselves. Such teachers at NGO schools are nominally volunteers (in receipt of small payments or stipends) because of restrictions on refugees' rights to work, and some may lack initial teacher training, having moved from their original profession into teaching, or may be qualified teachers in their home country, but lack the skills and resources for teaching in these very challenging circumstances.

For all these diverse groups of teachers, professional development is a priority (Ring and West, 2015). The TPD currently provided by NGOs can lack structure and certification, and is unlikely to address their needs, even though portable, meaningful certification for TPD is an especially important motivator for refugee teachers (ibid.). Providing TPD in the context of mass displacement is therefore a problem of both scale and quality of content. In the next section, we report also on the findings of the early stages of evaluating the potential for large-scale TPD in the especially challenging context of mass displacement.

\section{Methods}

\section{Evaluating the form of a MOOC for TPD}

To answer our first research question, we analysed data from three runs of two MOOCs funded by the Ufl Charitable Trust, Blended Learning Essentials: Getting Started (BLE1) and Blended Learning Essentials: Embedding Practice (BLE2), which were developed using a co-design methodology with stakeholders across the UK vocational education and training sector, and which aimed to scale up digital TPD in blended learning. Guided by Wenger et al.'s (2011) value creation approach to evaluating teacher professional development, we used a mixed methodology to make use of both 
quantitative and qualitative data from the platform analytics that recorded participants' activity, and from the survey and interviews that represented their perceptions.

The quantitative data come from the platform analytics, recording how participants engaged with the resources and activities provided by the MOOCs, and from those who responded to the pre- and post-course surveys (12 surveys in total, $n=2,387$ and $n=904$ respectively). The quantitative platform data sets were analysed using Python to identify patterns and yield insights, such as steps with unusually low completion rates. Survey data were analysed in Excel to produce descriptive statistics.

The qualitative data comes from the open-ended pre- and post-course survey questions, participants' discussion comments, 20 semi-structured interviews with volunteer participants and 46 responses to an in-course impact survey. The impact survey and interviews provide reports of the second-order impact of the MOOC on participants' own contexts of teaching. Inductive thematic analysis of the qualitative data was conducted in NVivo using Braun and Clarke's (2006) six-step process of data familiarization: generating initial codes, collating these into themes, reviewing the themes to ensure applicability in relation to the coded sections and entire data set, naming themes and selecting illustrative extracts.

\section{The potential of TPD MOOCs in the Lebanese context}

The second research question was to examine whether the form of a $\mathrm{MOOC}$ has potential for scaling up TPD in the context of mass displacement. This data set derives from two co-design workshops, in Beirut and Beqaa, with altogether 57 Syrian and Lebanese teachers, teacher educators and community researchers in Lebanon. The two workshops were part of a five-year programme of research by the RELIEF Centre, a transdisciplinary research collaboration that focuses on how to build a prosperous and inclusive future for communities affected by mass displacement (www.relief-centre. org). The workshops used the co-design process to develop and test the MOOC format for this context. The process began with discussions of participants' most challenging priorities for the $\mathrm{MOOC}$ to focus on. Activities were organized to enable participants to experience $\mathrm{MOOC}$ design, and to develop their own design ideas for each MOOC. Simultaneous audio translation and dual-language materials encouraged participation in Arabic and English throughout. In addition to discussions about course content, each workshop included discussions about the feasibility and applicability of MOOCs within the context of mass displacement. Participants provided feedback from group discussions to a digital audience response system using mobile phones, tablets and laptops. Plenary discussions focused on the key themes of priorities, activities, digital barriers and perceptions of feasibility, recorded by the research team. Participant contributions were thematically analysed in NVivo using the six-step process outlined above. The data presented here are the participants' reflections on the viability of MOOCs, including their concerns and recommendations.

\section{Results}

\section{The effectiveness of the MOOC for large-scale TPD}

The BLE MOOC data provides a strong case that a co-designed digital TPD can be effective in bringing TPD to scale, but there remain issues to resolve, particularly around securing sustainability of such projects. 


\section{Audience}

Evidence from platform data and post-course surveys shows that the courses reached the right audience:

- There were 13,065 active participants for BLE1 and 3,907 for BLE2 (51 per cent and 39 per cent of the enrolments respectively).

- Survey responses indicated that 57 per cent of participants were in teaching and education, with the majority in the VET sector (see Figure 1).

Vocational Education and Training

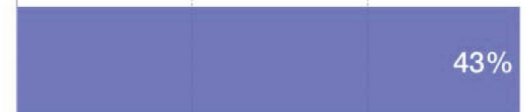

School Education

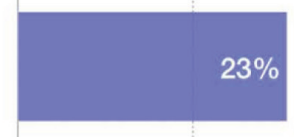

$0 \%$

$15 \%$

$60 \%$

Figure 1: Percentage of teaching-related BLE participants by sector

\section{Engagement}

Platform analytics show that participants engaged productively in the activities and with each other, in these terms:

- High levels of course participation and engagement, with active engagement achieved across all parts of the course, with over 80 per cent 'step visit to completion' rates in the majority of steps (see Figure 2).

- Contribution of over 40,000 comments in forum discussions (see Figure 3 for volume and pattern of comments in BLE1).

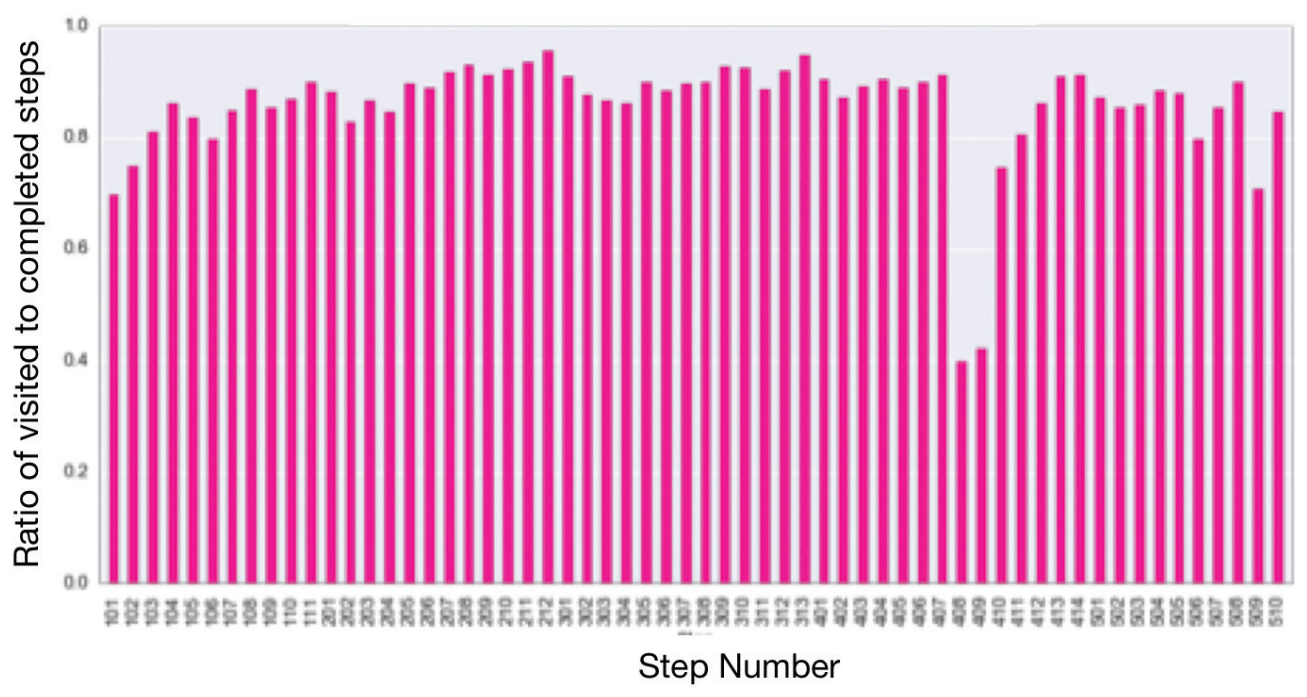

Figure 2: BLE1 Combined proportion of steps visited which were completed 


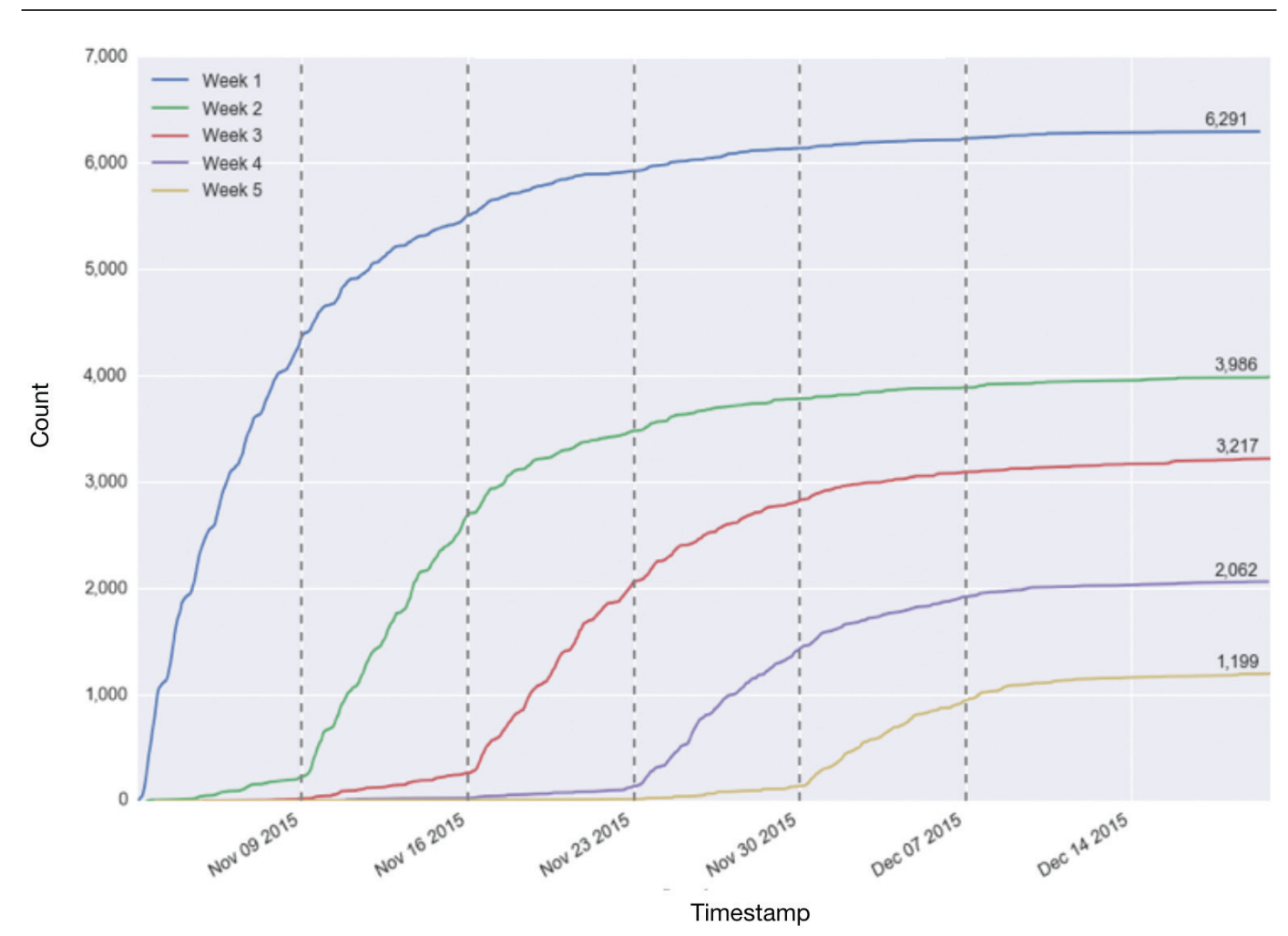

Figure 3: Volume and pattern of comments in BLE 1 run 1 by week

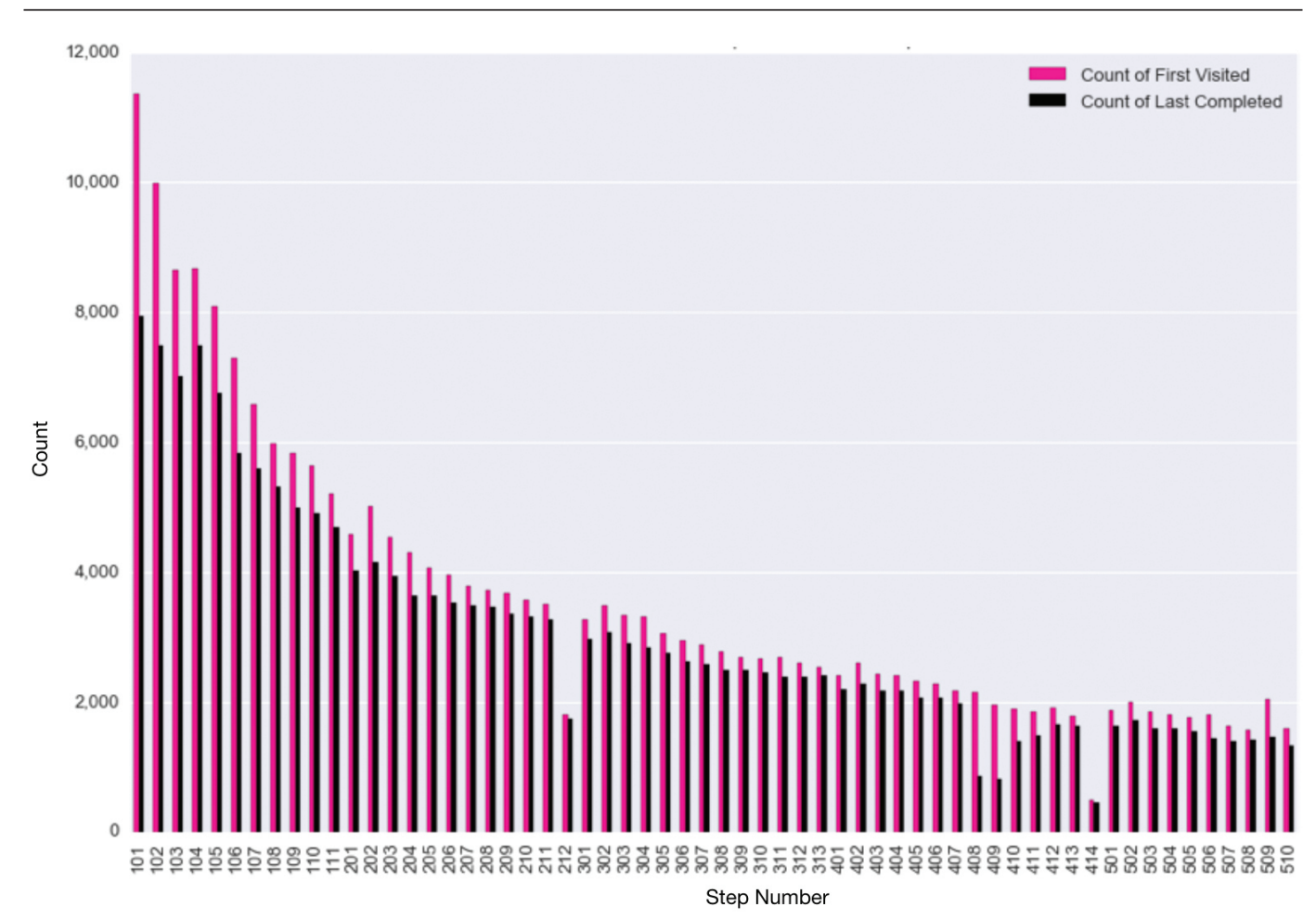

Figure 4: BLE1 Combined count of steps visited and completed

Participation decreased steadily across the duration of the course (see Figure 4), which is a typical pattern in MOOCs (Clow, 2013). However, MOOC participants have different motivations to study than traditional students (Kizilcec and Schneider, 2015), and may 
not necessarily intend to complete a course, though still get something useful from it. We know from other sources that the most likely reason for teacher drop-out is lack of time and inadequate local support (Laurillard and Deepwell, 2014).

\section{Satisfaction}

For participants who completed post-course surveys, satisfaction was high:

- the courses were rated 'good' or 'excellent' by 91 per cent of participants

- 95 per cent of participants stated that the courses had 'met' or exceeded' their expectations.

Comments in both the post-course surveys and participant interviews indicated that the courses were well designed, providing a high-quality learning experience:

I'm not the best person at navigating and on any type of online somethingor-other, and so I find it very user friendly for myself. I really like the structure. (Interview 14)

I like the fact that you could take the handouts and you could use them locally if you wanted to. (Interview 18)

[A course activity with Moodle] was something I'd never done before and it's helping me enormously now as I'm hosting all my projects on there. (Interview 11)

These data show that a very high proportion of completing participants find value in this form of TPD.

\section{Impact}

Our main interest is in second-order impact - what happens beyond the course. Almost 90 per cent of the post-course survey respondents reported that they were now aware of the many tools and technologies to support blended learning; 97 per cent agreed that blended learning approaches can enhance learning; 67 per cent felt that they now have the necessary skills to integrate technology into their teaching. Only 12 per cent felt that their 'limited knowledge' of blended learning would be a serious barrier to using it. Over 80 per cent of post-course survey respondents felt that it would improve their career prospects, while 15 per cent elected to purchase a statement of participation, indicating that they felt it would have currency in the job market.

Qualitative analysis of the peer review process, discussion activities and reflective questioning on the platform provided evidence of improving skills and confidence through peer support for learning. Many BLE participants observed - both in comments in the course and in the interviews - that access to the views and support of other learners provided the greatest learning opportunity:

[The discussions] were a great resource, positive in tone and practical in nature. (Interview 2)

Hearing practitioners' and learners' direct experience was really useful. (Interview 5)

I just found that I would be often, you know, quite tired at the end of the day but when I sat down, the learning essentials they were always messages, I just got engaged. (Interview 12) 
The BLE courses were designed to be collaborative, peer learning experiences, where teachers could learn with and from each other a range of techniques and skills that they could immediately use in their own professional contexts. Interviews showed that the courses were effective in enabling this to happen, with participants not only reporting using tools and approaches learnt in the course (often from other participants), but also encouraging others in their organizations to do the same. For example, one interviewee based in a multinational company required his team of two hundred trainers to take the course, while others recommended the course to colleagues, and teacher-trainers shared their learning with their trainees:

It is not just your continuing professional development (CPD), it's the others that you impart that information on. (Interview 14)

This second-order impact on participants' own contexts does suggest a multiplier effect, that is, that a TPD MOOC could have impact on many more teachers and learners beyond those it directly engaged.

\section{Sustainability}

Throughout the process of co-designing BLE, the course team and funder were focused on planning for sustainability, in several ways:

- Key stakeholders in the VET sector, such as innovative colleges and member organizations, were involved in the curriculum design and promotion of the course.

- The course team filmed classes and teachers in colleges that were implementing blended learning to show peers sharing their practice, rather than universities imposing generic solutions out of context.

- A team of 12 active 'digital champions', who were advanced in their practice of blended learning, supported course participants in local sessions using the MOOCs.

Our intention was that this process would not only create a genuinely collaborative, co-designed course, but that the stakeholders would have a sense of ownership of the course, and be motivated to continue to maintain and run it at the end of the project. The digital champions have been the backbone of the repeated runs of the course, acting as mentors to facilitate the discussions. Mentors have also presented at sector conferences and run workshops using the course materials to recruit more participants to the courses. However, despite this engagement from individuals, the former government-funded organizations in the UK that are responsible for TPD and digital methods in the VET sector, the Education and Training Foundation (a governmentbacked, sector-owned membership body, and a registered charity - www.et-foundation. co.uk/) and Jisc (a membership organization, owned by the HE and FE sectors in the UK - www.jisc.ac.uk/), are now only self-funded, and must develop their own forms of TPD, despite the acknowledged success of BLE, and the duplication of effort. Sustainability can only be secured through the University of Leeds taking on the costs of running them as part of its portfolio of MOOCs.

A better way to achieve sustainability would be to embed the course into training provision within the sector, so that running costs are incorporated into existing practices. The process needs more collective strategic leadership from government and sector organizations than it has received so far.

The lessons learnt from the BLE MOOCs, therefore, are that to achieve the optimal benefit from MOOCs for TPD, the biggest challenges are local support for 
teachers to complete, and sustainability in the longer term. The theory of change section below will discuss how to plan this from the outset.

\section{The potential for scaling up TPD in Lebanon}

The previous section has established in principle that MOOCs can be effective for TPD if we can address the issues of local support and sustainability. To test their feasibility for the context of mass displacement, for example in Lebanon, we took this question to the two workshops held in Lebanon combining Lebanese and refugee (Palestinian and Syrian) teachers, trainers and professionals.

We invited the workshop participants to consider the extent to which a MOOC could offer a viable solution to training teachers and other professionals in Lebanon. The feedback on this issue was positive, indicating its value (P1 and P2 indicate first and second workshop respectively, followed by participant number):

For teachers:

- 'we sometimes don't have a time to facilitate a workshop so we may ask our teachers to apply to online course instead' (P2-9)

- 'MOOC is so flexible and tailorable that it seems to adapt to the needs of any knowledge and professionalism seeker in this domain' (P1-9)

- 'I think it is important that we share our collective research and development efforts' (P2-10)

- 'to develop the skills of modern education and training and the creation of advanced technological methods' (P2-3)

- 'preparation of trained teachers who can participate in the teaching process in Lebanese schools' (P2-14).

For a contemporary approach:

- 'It's a practical method because technology has invaded the world' (P2-4)

- 'Education is changing anyway' (P1-2).

However, there were many reservations expressed by the participants at both workshops, categorized as:

- the lack of stable internet access

- the skills and disposition of potential participants

- teachers might need to be supported to embrace a new culture of learning

- teachers do not all have the capacity to study and work at the same time

- the language of instruction is English.

Discussion of these barriers to engaging in MOOCs in the context of Lebanon led to the participants identifying a number of recommendations for the design and implementation of the MOOCs:

- certification (ideally endorsed by the ministry)

- an emphasis on the practical application of theoretical concepts

- interactivity: 'it needs to be interesting and full of various media elements' (P1-4)

- designed with the refugee community as 'decision makers': 'focus on the needs of the community rather than implementing something applied elsewhere' (P1-15)

- blended learning support (for example, at a computer lab with a facilitator) to help 'ensure quality of training' (P1-23). 
The findings from these workshops indicated that there is potential for co-designed digital learning to meet teacher professional development needs, but many challenges remain.

The question for this project, therefore, is how to respond effectively to the challenges identified. How can we shift our focus to make refugees decision makers, and genuinely involve the whole community - Lebanese, Palestinian and Syrian teachers and teacher trainers - in the co-design of the MOOC?

The next section outlines our theory of change to show how we will mitigate the issues identified so far, by co-designing sustainable MOOCs that are owned by the community in all its diversity.

\section{Theory of change model}

We have established that digital methods in the form of MOOCs provide effective TPD, and that this could work on the large scale if there is local support for teacher engagement and sustainability. We have also established that there is an interest in using MOOCs to unify and scale up TPD in the Lebanese context of mass displacement. Specific challenges still exist, however. Therefore, it is important to articulate our strategy and the steps we can take to mitigate them. Using the lessons learnt from the BLE programme and the co-design workshops in Lebanon, we have developed the co-design approach as a theory of change, to guide our attempts to overcome these challenges, which we will test in practice.

A theory of change (ToC) is described by Laing and Todd (2015: 3) as a theorybased methodological approach to 'planning, implementing or evaluating change at an individual, organisational or community level'. A ToC replaces what can often be crude output measures with a complex evaluation framework of initiatives, appropriate for areas such as education, community development and public health. A ToC is developed by researchers to create a plan for action that identifies the steps that the project will undertake to achieve the anticipated effects. The activities directed by the ToC need to be closely monitored throughout the project, requiring a portfolio of data to be collected as the evidential data for the success or failure of each step of the process (Laing and Todd, 2015).

We have created a theory of change that elaborates the co-design model that we are applying in Lebanon to cover an end-to-end strategy for the project overall. We draw on an early but comprehensive definition of co-design by Penuel et al. (2007), who emphasize the importance of, for example:

- a concrete, tangible innovation challenge

- an analysis of current practices

- a flexible curriculum target

- a bootstrapping event or process to catalyse the team's work.

These are reflected in the successive stages of the model.

By using an online course platform for the TPD course itself, we can carry the co-design process through from stakeholder engagement to the way in which all course participants engage with innovative approaches to teaching. In this way, the online course becomes an orchestrated process of knowledge building by the whole community of participants on how to teach in the most challenging contexts, embedded in local practice, and thereby self-sustained beyond the end of funding. Figure 5 shows how we are conceptualizing the stages of co-design, and the corresponding threats to successful implementation, at each stage that might be mitigated through the codesign process. Table 1 shows how these are manifested in our project in Lebanon. 


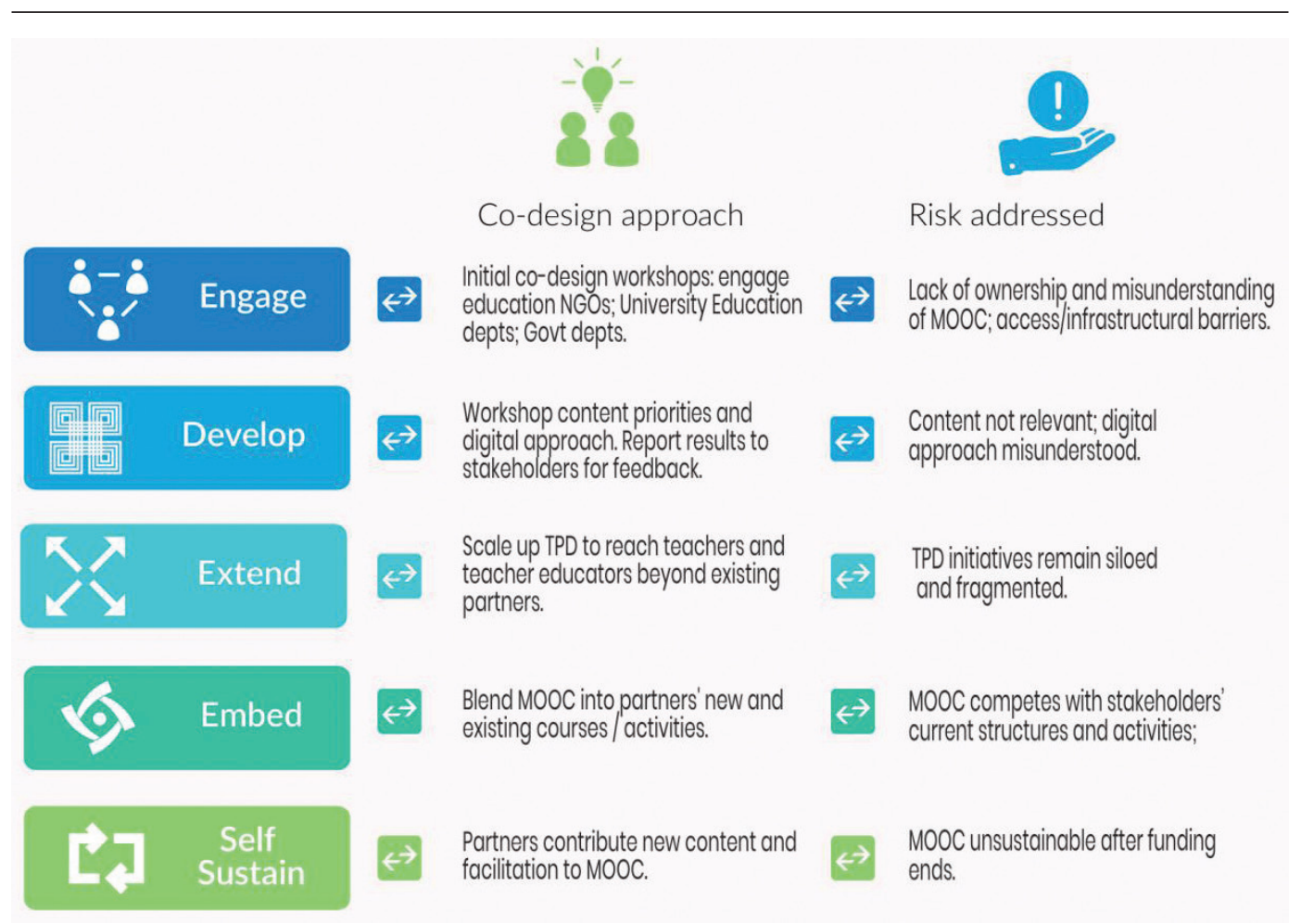

Figure 5: Theory of change for using MOOCs to scale up TPD in Lebanon

Table 1: Instantiation of theory of change model for TPD MOOC based on RELIEF Centre research in Lebanon

\begin{tabular}{|c|c|c|}
\hline & Co-design activities & Aims \\
\hline \multirow[t]{2}{*}{ Engage } & \multirow{2}{*}{$\begin{array}{l}\text { Workshops and meetings with: MEHE, } \\
\text { CERD, Lebanese American University, } \\
\text { Lebanese University, UNRWA, UNHCR, } \\
\text { NGOs }\end{array}$} & $\begin{array}{l}\text { Builds ownership and understanding, } \\
\text { using existing work, to clarify concept }\end{array}$ \\
\hline & & $\begin{array}{l}\text { Co-designed plans facilitate teachers' } \\
\text { digital engagement }\end{array}$ \\
\hline \multirow[t]{2}{*}{ Develop } & \multirow{2}{*}{$\begin{array}{l}\text { Three-day MOOC design workshop } \\
\text { with all partners; filming teachers in } \\
\text { partners' schools; obtaining partner } \\
\text { feedback at all stages of MOOC design }\end{array}$} & $\begin{array}{l}\text { Content is co-designed and represents } \\
\text { localized issues }\end{array}$ \\
\hline & & $\begin{array}{l}\text { Digital collaboration across countries } \\
\text { engages local partners }\end{array}$ \\
\hline \multirow[t]{2}{*}{ Extend } & \multirow[t]{2}{*}{$\begin{array}{l}\text { Creation of MOOC on two platforms: } \\
\text { Edraak and FutureLearn }\end{array}$} & $\begin{array}{l}\text { Reduces dominance of English to } \\
\text { improve global access to free resource }\end{array}$ \\
\hline & & $\begin{array}{l}\text { MOOC orchestrates collaboration } \\
\text { across many contexts of mass } \\
\text { displacement, and across public, } \\
\text { private, NGO sectors }\end{array}$ \\
\hline \multirow[t]{2}{*}{ Embed } & \multirow[t]{2}{*}{$\begin{array}{l}\text { Co-designed blended programmes at } \\
\text { LAU, Lebanese University and UNHCR }\end{array}$} & $\begin{array}{l}\text { MOOC becomes core to existing TPD } \\
\text { activities }\end{array}$ \\
\hline & & $\begin{array}{l}\text { Digital approach is scaffolded for } \\
\text { organizations to develop understanding }\end{array}$ \\
\hline $\begin{array}{l}\text { Self- } \\
\text { sustain }\end{array}$ & $\begin{array}{l}\text { Co-designed certification pathways; } \\
\text { capability building in digital learning }\end{array}$ & $\begin{array}{l}\text { Sustainability improves by developing } \\
\text { partner expertise and capacity for } \\
\text { existing and new MOOC initiatives }\end{array}$ \\
\hline
\end{tabular}




\section{Stages of co-design}

\section{Engage}

The importance of engaging local stakeholders derives from the need identified from the evaluation of BLE to ensure local support of teachers from the start, and to foster ownership for sustainability.

Currently, the educational landscape of Lebanon is complex and disconnected. There are many initiatives, and much good work being done. However, there are many children who need access to good-quality education who are not being reached. Our strategy is, therefore, to engage from the start with the many stakeholders in TPD in Lebanon - NGOs, UNWRA, MEHE, CERD, and public and private universities offering initial and continuing teacher training.

The aim is to engage the key local stakeholders in the innovation challenge: a new type of TPD course adapted to the needs of teachers innovating in a context of mass displacement.

Analysis of research distils educational research findings for their practical implications, but there has been too little practical research and too few clear findings produced to be of practical value to a teacher in a long-term refugee camp. There is new pedagogical knowledge to be developed, for example, about how best to teach written fluency to a child who may have been traumatized. What stories do you ask them to write about their family? The initial Engage stage used local collaborative workshops in Lebanon to identify the curriculum targets for the MOOCs, and the stakeholders to be involved in the later stages.

Engaging stakeholders in the co-design of the course they need is an opportunity for them to build their own areas of responsibility for developing the community knowledge about how to teach in this particular context. The inaugural design workshops elicited ideas, experiences and cases from local professionals, to catalyse the work of the course team.

\section{Develop}

The analysis of the workshop outputs guides the way we develop the initial course outline. It is sent to co-designers for feedback, and to suggest or volunteer as case studies for the videos. As with BLE, we are taking our cameras to the teachers teaching in refugee camps and formal schools to capture their practice. We are negotiating with stakeholder agencies to gain permission to film in all forms of provision, including public, private and UNRWA schools. Successive versions of the course design are checked with co-designers at each stage.

The intention is that the TPD MOOCs will open up the classrooms of different kinds of teachers who are inventing ways of dealing with the challenges of mass displacement in their own context, to enable teachers to learn from and with each other, bringing together teachers who typically occupy very separate domains. In particular, by enabling teachers who are refugees themselves to share the teaching knowledge they have developed, we aim to challenge the dominant discourse of 'refugee as burden' by showcasing the resources, skills and understanding they bring to teaching.

We will counter external forces that threaten to undermine the project (for example, poor teacher motivation or competition between TPD providers) by involving these stakeholders and the teachers themselves in the co-design of the course. We will adopt an approach informed by appreciative inquiry (Shuayb, 2014a) to discover 
effective workarounds and solutions from current practice, and make use of these in the TPD design.

\section{Extend}

This stage uses the principal research tool, in our case the MOOC platforms, as the way to extend the lessons learnt within the local context of Lebanese refugees to the wider community of professionals across the world who are engaged in similar projects.

The course uses online activities, discussions and requirements for participant contributions to extend the co-design of community knowledge of effective practices to a global audience of both practising and potential community-based researchers. The course activities enable these professionals to learn from ideas, practices, solutions and critiques covered in the video case studies, from contexts similar to their own, and, through the discussions and participant contributions, from a wide range of challenging contexts beyond those provided by the course team. The nature of MOOC platforms supports the scaling up; the design of the course supports the collaborative knowledge building.

\section{Embed}

Co-design will extend to the next stage of blending the MOOC into existing TPD provision by working with stakeholders to make the course a fundamental part of their course offerings. This will also help us respond to potentially derailing forces improving retention rates by face-to-face support, providing reliable access to power, equipment and broadband. In return, the stakeholders will benefit from professional development in blended learning, and a relevant, innovative, co-designed, open educational resource to enhance their current provision.

Positive experiences with using the MOOC will lead to the course being embedded in the stakeholders' current structures, rather than merely running alongside them.

\section{Self-sustain}

If they are involved in the co-design process throughout, there is a greater probability that the stakeholders will be committed to running and maintaining the course so that it becomes self-sustaining. Balancing initial financial investment with the potential income stream from future runs through paid upgrades will be central to showing how this model can work.

The sustained nature of these orchestrated knowledge-building activities across successive course runs will facilitate evidence gathering of long-term impact, which is a key motivation for our research and provides the justification for global investment in digital TPD at scale.

The instantiation of the ToC model provided by the TPD MOOC (working title: Educators for Change) is shown in Figure 5 and Table 1. We have demonstrated the potential of the $\mathrm{MOOC}$ through the engagement so far of local stakeholders in the initial stages. Testing the model overall will happen at each stage as we evaluate the effectiveness of the TPD MOOC at scale, and over the long term, for this context.

\section{Testing the model}

Current feedback on the first two stages of this process is encouraging. We have worked with a range of Lebanese organizations to develop the course, and are now 
working with the LAU and the Lebanese University to assist with running it, and then embedding it within their existing courses. Co-designers from across TPD provision (including government and NGOs) in Lebanon are enthusiastic about using blended learning in innovative ways. A workshop held in London in August 2018, away from the concerns of everyday Lebanon, enabled these stakeholders to forge alliances that did not exist before. Key design decisions have already been made in the light of the feedback from stakeholders and teachers. For example, we are committed to creating the courses - including the videos - in both English and Arabic to meet the varied needs of all participants. This entails a dual-platform approach, with courses being mirrored on the Arabic-language MOOC provider Edraak, and the English-language FutureLearn.

The evaluation framework will use the data collected at each stage of the process: levels of engagement by stakeholders; feedback on the courses as they develop; data from the course runs; case studies of instances of embedding; and extent of the transfer of responsibility to local organizations to assess sustainability.

The project is ambitious, but by working to the stages we believe are required to make it a success, articulated as a ToC, we can acknowledge the challenges, show how we intend to meet them, evaluate our progress and refine our model.

\section{Concluding points}

Our aim is to develop a ToC model that has been thoroughly tested and can be applied anywhere that mass displacement creates a need for TPD at scale. The geopolitics of war, climate change and social inequality has created an increasingly mobile world, where mass displacement has ceased to be an anomaly. Enduring solutions for these unstable times are necessary. Enabling people on the move to access quality education is part of this, and scaling up TPD using digital methods is a step towards this goal.

\section{Notes on the contributors}

Eileen Kennedy is Senior Research Associate at the Centre for Global Higher Education and the RELIEF Centre. She is based at the UCL Knowledge Lab, UCL Institute of Education, researching ways of enhancing the online learning experience and sharing practice in online and blended learning. This involves developing learning design tools (with Diana Laurillard), creating teacher communities online (for example, through MOOCs) and researching the experience of learning online. Previously she taught sociology at various universities for over ten years.

Diana Laurillard is Professor of Learning with Digital Technologies, UCL Knowledge Lab. She was formerly Head of the e-Learning Strategy Unit at the Department for Education and Skills (2002-5), Pro-Vice Chancellor for learning technologies at the Open University (1995-2002) and a member of the Dearing Committee. Projects in which she has been involved include: developing the Learning Designer and Course Resource Appraisal Modeller tools for teachers; MOOCs on Blended Learning Essentials for teachers; Future Education in the RELIEF Centre; neural-informed game-based interventions for low-progress learners with the Learning Sciences Lab Singapore; and Teacher Community Knowledge with the AICFE, Beijing. Her publications include Teaching as a Design Science (Routledge, 2012). 


\section{References}

Akar, B. and Van Ommering, E. (2018) 'An emerging framework for providing education to Syrian refugee children in Lebanon'. In Pace, M. and Sen, S. (eds) Syrian Refugee Children in the Middle East and Europe: Integrating the young and exiled. London: Routledge, 59-72.

Beals, E. (2014) 'Second shift schools offer hope to young Syrians'. UNHCR News, 24 February. Online. http://tinyurl.com/y3wwa4ck (accessed 7 April 2019).

Braun, V. and Clarke, V. (2006) 'Using thematic analysis in psychology'. Qualitative Research in Psychology, 3 (2), 77-101.

Burns, M. and Lawrie, J. (eds) (2015) Where It's Needed Most: Quality professional development for all teachers. New York: Inter-Agency Network for Education in Emergencies. Online. http://tinyurl.com/y6qacjcs (accessed 7 April 2019).

Clow, D. (2013) 'MOOCs and the funnel of participation'. In LAK '13: Proceedings of the Third International Conference on Learning Analytics and Knowledge. New York: Association for Computing Machinery, 185-9.

CLS (Centre for Lebanese Studies) (2019a) 'Refugees Access to Education Campaign'. Online. http://tinyurl.com/yylyc9s9 (accessed 7 April 2019).

CLS (Centre for Lebanese Studies) (2019b) 'Working towards an inclusive education system for Syrian and Lebanese children in public schools'. Online. http://tinyurl.com/y6k83o4g (accessed 7 April 2019).

Darling-Hammond, L. (2000) 'Teacher quality and student achievement : A review of state policy evidence'. Education Policy Analysis Archives, 8 (1), 1-42.

El-Ghali, H.A., Berjaoui, R. and DeKnight, J. (2017) Higher Education and Syrian Refugee Students: The case of Lebanon: Policies, practices, and perspectives. Beirut: UNESCO Regional Bureau for Education in the Arab States.

Hollands, F.M. and Tirthali, D. (2014) MOOCs: Expectations and reality. New York: Center for Benefit-Cost Studies of Education.

Kizilcec, R.F. and Schneider, E. (2015) 'Motivation as a lens to understand online learners: Toward data-driven design with the OLEl scale'. ACM Transactions on Computer-Human Interaction, 22 (2), 1-24.

Laing, K. and Todd, L. (eds) (2015) Theory-Based Methodology: Using theories of change for development, research and evaluation. Newcastle: Research Centre for Learning and Teaching.

Laurillard, D. (2016) 'The educational problem that MOOCs could solve: Professional development for teachers of disadvantaged students'. Research in Learning Technology, 24, 1-17. Online. http://tinyurl.com/y5jju422 (accessed 5 April 2019).

Laurillard, D. and Deepwell, M. (2014) ALT Survey on the Effective Use of Learning Technology in Education. Oxford: Association for Learning Technology. Online. http://tinyurl.com/nec9vgh (accessed 7 April 2019).

Laurillard, D. and Kennedy, E. (2017) The Potential of MOOCs for Learning at Scale in the Global South (CGHE Working Paper 31). London: Centre for Global Higher Education. Online. http://tinyurl.com/y62n5dze (accessed 7 April 2019).

Maamari, D. (2018) 'Centre for Educational Research and Innovation'. Paper presented at the Educators for Change RELIEF Centre Workshop. London, 8 August.

Oyo, B. and Kalema, B.M. (2014) 'Massive open online courses for Africa by Africa'. International Review of Research in Open and Distance Learning, 15 (6), 1-13. Online. http://tinyurl.com/ y3ac6z3t (accessed 5 April 2019).

Penuel, W.R., Roschelle, J. and Shechtman, N. (2007) 'Designing formative assessment software with teachers: An analysis of the co-design process'. Research and Practice in Technology Enhanced Learning, 2 (1), 51-74.

Richardson, E., MacEwen, L. and Naylor, R. (2018) Teachers of Refugees: A review of the literature. Reading: Education Development Trust. Online. http://tinyurl.com/y2f2r3fh (accessed 7 April 2019).

Ring, H.R. and West, A.R. (2015) 'Teacher retention in refugee and emergency settings: The state of the literature'. International Education Journal: Comparative Perspectives, 14 (3), 106-21.

Rohs, M. and Ganz, M. (2015) 'MOOCs and the claim of education for all: A disillusion by empirical data'. International Review of Research in Open and Distributed Learning, 16 (6), 1-19. Online. http://tinyurl.com/y55ukd8x (accessed 5 April 2019).

Sesnan, B., Allemano, E., Ndugga, H. and Said, S. (2013) Educators in Exile: The role and status of refugee teachers. London: Commonwealth Secretariat.

Shuayb, M. (2014a) 'Appreciative inquiry as a method for participatory change in secondary schools in Lebanon'. Journal of Mixed Methods Research, 8 (3), 299-307. 
Shuayb, M. (2014b) 'The art of inclusive exclusions: Educating the Palestinian refugee students in Lebanon'. Refugee Survey Quarterly, 33 (2), 20-37.

Shuayb, M., Al Maghlouth, N., Held, K., Ahmad, N., Badran, T. and Al Qantar, S. (2016) An Education for the Future: The schooling experience of Syrian refugee children in Lebanon and Germany. Beirut: Centre for Lebanese Studies.

Shuayb, M., Makkouk, N. and Tuttunji, S. (2014) Widening Access to Quality Education for Syrian Refugees: The role of private and NGO sectors in Lebanon. Beirut: Centre for Lebanese Studies.

UNHCR Operational Data Portal (2018) 'Situation Syria Regional Refugee Response'. Online. https://data2.unhcr.org/en/situations/syria/location/71 (accessed 20 August 2018).

Wall, M., Otis Campbell, M. and Janbek, D. (2017) 'Syrian refugees and information precarity'. New Media and Society, 19 (2), 240-54.

Wenger, E., Trayner, B. and De Laat, M. (2011) Promoting and Assessing Value Creation in Communities and Networks: A conceptual framework (Rapport 18). Heerlen: Ruud de Moor Centrum. 